\title{
Debates historiográficos
}

\author{
Historiographical debates
}

HAHN, Fábio André; MEZZOMO, Frank Antonio; MYSKIW, Antônio Marcos. Ensaios historiográficos: temas, tendências e interpretações. Campo Mourão: Editora da FECILCAM, 2010, 226 p.

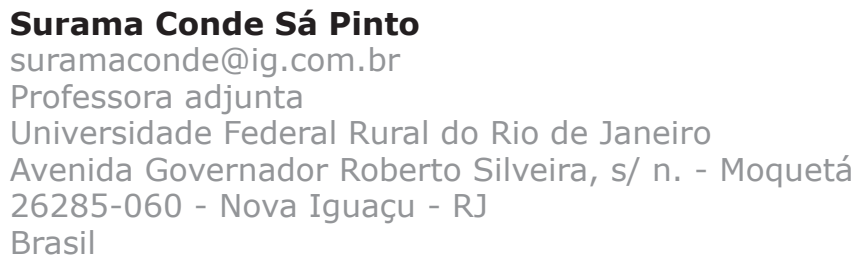

Palavras-chave

Historiografia; Teoria da história; Metodologia.

Keywords

Historiography; Theory of history; Methodology. 
Não há avanços na pesquisa sem diálogo entre diferentes especialistas, sem debates conceituais ou discussões de temas, tendências e interpretações teórico-metodológicas. O aumento do número de Instituições de Ensino Superior (IES) no Brasil, assim como a crescente formação de grupos de pesquisa, tem estimulado sobremaneira a integração de pesquisadores e a divulgação de sua produção.

O livro em questão, organizado por Fábio Hahn, Frank Mezzomo e Antônio Myskiw, autores de estudos sobre pensamento político moderno, práticas religiosas e história agrária, respectivamente, é o exemplo claro de um esforço de divulgação da investigação desenvolvida por um grupo de pesquisadores reunidos no Grupo de Pesquisa Cultura e Relações de Poder, criado em 2007, na Faculdade Estadual de Ciências e Letras de Campo Mourão (FECILCAM).

Trata-se de uma coletânea, dividida em duas partes (Tendências e debates historiográficos; e Oeste do Paraná: temas e interpretações), que reúne ensaios variados focalizando alguns caminhos trilhados pela pesquisa histórica contemporânea, sobretudo no que diz respeito à multiplicidade de objetos, abordagens e aportes teóricos. Sem perder de vista a riqueza de possibilidades ensejada pelo debate interdisciplinar, os autores descortinam temas variados que apresentam como eixo central a questão da escrita da história.

Essa proposta está presente no capítulo intitulado "Paradigmas da historiografia marxista no século XX: notas de leitura", de Petrônio Domingues. Nesse estudo, num primeiro momento, Domingues recupera as bases do materialismo histórico de Karl Marx, utilizando o prefácio do clássico Para a crítica da economia política, para em seguida destacar as diferentes apropriações e leituras sobre a relação estabelecida entre estrutura e superestrutura na obra do filósofo alemão. Na segunda parte do texto, o autor discute as inovações ensejadas na historiografia marxista a partir das obras de Antonio Gramsci (18911937), Louis Althusser (1918-1990) e Edward Palmer Thompson (1924-1993). Dos três, Althuser, autor bastante influenciado pelo estruturalismo, é o menos trabalhado. A ênfase recai na consagrada contribuição de Edward Thompson para o século $X X$, sobretudo no que diz respeito à importância conferida à experiência humana, categoria chave na construção do conhecimento histórico no modelo teórico propugnado pelo inglês. Apesar do interessante exercício de reflexão sobre como os historiadores marxistas têm desenvolvido uma nova proposta para recuperar o lugar da pesquisa histórica como fundamento da interpretação, a discussão seria sensivelmente enriquecida se Domingues tivesse utilizado diretamente os textos dos próprios autores citados, e não o trabalho de comentaristas para analisar essas contribuições, conforme é feito na maior parte do capítulo.

Tarcísio Vanderlinde é outro autor que na coletânea se dedica à discussão de questões teóricas e metodológicas relacionadas ao trabalho de investigação histórica. Seu foco está voltado para o debate relativo à autenticidade e origem de documentos, os perigos da mediação dos mesmos, a intencionalidade dos textos e possibilidades de leituras, num recorte que privilegia o século XVI. De forma bastante didática, Vanderline recupera as contribuições de Roger Chartier relativas às práticas de leitura e o método indiciário de Carlo Ginzburg para 
reafirmar alguns ensinamentos dos pais da Escola dos Annales, Bloch (s/d) e Febvre (1970): o de que a tarefa do historiador é compreender; o de que o acesso ao passado é sempre feito de forma indireta, mediada; e aquele segundo o qual cada época constrói mentalmente a sua representação do passado histórico.

Questões relacionadas ao conceito e tendências da história intelectual são abordadas no capítulo assinado por Fábio Hahn. Ao refletir sobre as dificuldades de definição termo, Hahn recupera a discussão feita nas tradições francesa, norte-americana e italiana, além de mapear as linhas mestras desse debate no Brasil, capitaneado por Francisco Falcon. ${ }^{1}$ No âmbito das tendências da história intelectual, embora reconheça a existência de um grande número de caminhos possíveis, o autor destaca três correntes: a contextualista, de Quentin Skinner e John Pocock, a hermenêutica, de Hans-Georg Gadamer, e o desconstrucionismo de Jacques Derrida. Com base no diálogo com essas correntes, Hahn analisa alguns conceitos que, na sua perspectiva, formam a base estrutural da história intelectual.

Como foi construída discursivamente a ideia de nacionalidade no Brasil ao longo do século XIX e em inícios do XX? Como foi tratada a questão racial? Essas questões são debatidas no capítulo de José Carlos dos Santos, que fecha a primeira parte do livro. A temática já foi objeto de estudo de diferentes especialistas como Skidmore (1976), Lippi (1990), Carvalho (1990), Sandes (2000) e Guimarães (2006), ignorados pelo autor. Em "A Hermenêutica da nação", Santos, professor da UNIOESTE, em vez de dialogar com essa produção, 270 opta por mergulhar no romance histórico Choque das Raças, de Monteiro Lobato, para discutir a racialidade e a formação do caráter do brasileiro.

A segunda parte do livro reúne trabalhos específicos sobre o Paraná abarcando diferentes temporalidades e temáticas. Falta entre a primeira e a segunda parte uma maior relação, já que no segundo bloco os autores não retomam as reflexões desenvolvidas no primeiro.

Abrindo essa seção, o capítulo assinado por Antônio Marcos Myskiw ao mesmo tempo em que reafirma a importância da história regional produzida nas universidades públicas do estado, como a UFPR, a UEM, a UEL a UNIOESTE e o UNICENTRO, destaca a carência de reflexões em relação a essa produção. Myskiw visa preencher nesse trabalho uma lacuna detectada na história do Oeste do Paraná para o período compreendido entre as últimas décadas do século XIX e as primeiras do século XX, explorando a potencialidade e riqueza dos relatos de viagens, escritos e publicações entre os anos de 1876 e 1946. De acordo com o autor, essas narrativas acabaram constituindo importantes fontes na fundamentação de uma identidade regional paranaense.

O Oeste do Paraná também é trabalhado por Marco Aurélio Sella. O enfoque, contudo, é voltado para a história das mulheres. No capítulo "Mulheres, historiografia, gênero e o Oeste do Paraná", num primeiro momento, Sella discute questões que há muito povoam o universo dos debates empreendidos

${ }^{1}$ Curioso é que o autor não tem a mesma visão de Falcon de que a história intelectual no Brasil há muito caminha a passos lentos. Hahn é mais otimista. 
pelos especialistas nas relações de gênero. Em seguida, analisa alguns estudos realizados a partir desse viés para o período da colonização local. O objetivo precípuo do trabalho é dar visibilidade às mulheres, personagens ausentes na produção historiográfica relativa à construção da região, mostrando a importância do papel por elas desempenhado nesse processo.

Na sequencia, o capítulo escrito por Márcia Regina Ristow se reporta ao debate sobre o saber médico e a saúde pública no Paraná, entre as décadas de 1930 e 1940. Para estudar a formação da inteligentsia médica e o desenvolvimento do sanitarismo no estado, Ristow parte do pressuposto de que a assistência é uma prática discursiva fundadora na definição de políticas de constituição de identidades, concretizada tanto na consolidação do conhecimento médico sobre o corpo quanto de uma identidade nacional. A análise empreendida pela autora, estruturada com base numa pesquisa documental bem conduzida, destacando-se entre as fontes utilizadas os Ofícios da Inspetoria de Profilaxia da Lepra e das Doenças venéreas, poderia ter sido enriquecida caso a autora comparasse a experiência paranaense com a de outros estados. Na realidade esse é um traço comum à maioria dos textos dessa seção: a escrita de uma história regional que se encerra em si mesma, sem fazer relação com o nacional, sem fazer relação com outras experiências.

Finalizando o livro, Frank Antônio Mezzano lança-se no desafio de trabalhar com outro setor de ponta da pesquisa histórica: o estudo de trajetórias e biografias. Focalizando o campo religioso católico do Oeste do Paraná, Mezzano reconstitui e analisa a trajetória e a biografia de Dom Olívio Aurélio Fazza, bispo da diocese de Foz do Iguaçu entre 1978 e 2002, para compreender a ação da Igreja Católica numa região de fronteira. Para realizar essa empreitada, o autor faz uso de alguns escritos produzidos por agentes da Igreja e de entrevistas. Um dos méritos de sua análise é abrir espaço para a reflexão sobre a questão do indivíduo e a construção dos laços sociais, problemática que há muito vem mobilizando os historiadores.

Num balanço geral, os capítulos veiculados na primeira parte do livro, voltados para um público mais amplo, refletem, simultaneamente, tendências abertas com as mudanças processadas na escrita da história nas últimas décadas, elementos que remetem à herança dos Annales (sobretudo no que diz respeito à importância conferida ao método comparativo, à ampliação da noção de documentos e as diferentes formas de leitura) e o espaço que vem sendo conquistado pela chamada história intelectual. Já os textos que fazem parte da segunda seção são direcionados, em particular, para os interessados e estudiosos da história do Paraná.

Por outro lado, para além de um roteiro sucinto de questões e problemáticas, em seu conjunto, as análises desenvolvidas pelos autores do livro destacam os desafios e problemas colocados aos historiadores nos planos teórico e metodológico, além de linhas e tendências da produção historiográfica mundial e nacional. Ensaios Historiográficos pode ser considerado ainda um cartão de visitas do Grupo de Pesquisa Cultura e Relações de Poder da FECILCAM. 


\section{Referências bibliográficas}

BLOCH, Marc. Introdução à História. Lisboa: Europa-América, s/d.

CARVALHO, José Murilo de. A formação das almas: o imaginário da República no Brasil. São Paulo: Companhia das Letras, 1990.

FEBVRE, Lucien. O problema da descrença no século XVI: a religião de Rebelais. Lisboa: Editorial Início, 1970.

GUIMARÃES, Lucia Maria Pascoal. Da escola paladina ao silogeu: Instituto Histórico e Geográfico Brasileiro (1889 - 1938). Rio de Janeiro: Editora do Museu da República, 2006.

OLIVEIRA, Lúcia Lippi. A questão nacional na primeira República. São Paulo: Editora Brasiliense, 1990.

SANDES, Noé Freire. A invenção da nação: entre a monarquia e a república. Goiás: Editora da UFG, 2000.

SKIDMORE, Thomas. Preto no branco: raça e nacionalidade no pensamento brasileiro (1870-1930). Rio de Janeiro: Paz e Terra, 1976. 